Revista de la red interuniversitaria de estudios sobre las literaturas rioplatenses contemporáneas en Francia

$22 \mid 2021$

¿Cómo se cuenta una vida? El retorno de lo biográfico en la literatura rioplatense contemporánea

\title{
El expediente Lamborghini
}

Le dossier Lamborghini

The Lamborghini File

\section{Nieves Battistoni}

\section{(2) OpenEdition}

\section{Journals}

Edición electrónica

URL: http://journals.openedition.org/lirico/10114

DOI: 10.4000/lirico.10114

ISSN: 2262-8339

Editor

Réseau interuniversitaire d'étude des littératures contemporaines du Río de la Plata

Referencia electrónica

Nieves Battistoni, «El expediente Lamborghini», Cuadernos LIRICO [En línea], 22 | 2021, Publicado el 10 marzo 2021, consultado el 16 marzo 2021. URL: http://journals.openedition.org/lirico/10114 ; DOI: https://doi.org/10.4000/lirico.10114

Este documento fue generado automáticamente el 16 marzo 2021.

\section{c) (i) $\Theta($}

Cuadernos LIRICO está distribuido bajo una Licencia Creative Commons Atribución-NoComercialSinDerivar 4.0 Internacional. 


\title{
El expediente Lamborghini
}

\author{
Le dossier Lamborghini \\ The Lamborghini File
}

Nieves Battistoni

Desconfía de los envidiosos y de los amargados. No concedas lugar a los rumores maliciosos. No abrumes a quien has elegido para escribir su

biografía. No te regocijes con sus errores y pequeñeces. No lo trates más rudamente que lo que querrías que te traten a ti. Sírvele antes de abogado que de juez. Ámalo, o trata de amarlo, ya que has elegido acercarte a él.

(Peeters, "Vuelo Abu Dabi-París, 19 de marzo de 2007", Tres años con Derrida).

Invariablemente, cada vez que a Ricardo Strafacce le pregunten qué lo motivó a escribir la biografía de Osvaldo Lamborghini, dirá que quiso saber cómo era el hombre que escribía así1. La solución se replica como un leitmotiv en las entrevistas que concede y figura por escrito en el mínimo prólogo a la monumental biografía (2008:11). Pero, con ser invariable, no es la única: hay, además, una "motivación formal", especie de reacción contra la incomodidad que a Strafacce le provoca el discurso crítico: "pensaba -y sigo pensando- que el género biográfico es una de las formas más útiles y sanas de escribir sobre un autor. Los discursos sometidos al régimen del comentario (en el sentido de Foucault) se encuentran, creo, en un callejón sin salida, chapoteando entre la tautología y la mala fe" (2014 Web). Es decir que habría una manera inútil e insana ¿académica?- de escribir sobre un autor. Entonces, ¿por qué no escribir un libro útil?, ¿por qué no la biografía de Osvaldo Lamborghini y, de ese modo, darle a la Historia de la Literatura Argentina - no al campo literario, no a la crítica- el capítulo que le faltaba?

En general, las motivaciones declaradas de la escritura biográfica suelen parecerse a la curiosidad primera de Strafacce. "Quería saber cómo era la mujer que escribió eso", dice Mariana Enriquez sobre Silvina Ocampo; "quería saber con qué experiencias se había hecho escritor", dice Carlos María Domínguez, biógrafo de Juan Carlos Onetti; 
"quería saber cómo se convierten en escritores los que sí lo son", dice Patricio Zunini a propósito de Rodolfo Fogwill (2016 Web). Pero, mientras la mayoría de los biógrafos y biógrafas que podríamos incluir en una suerte de pequeño auge biográfico de la literatura argentina contemporánea ${ }^{2}$ opone cierta resistencia a reconocer que ha escrito una biografía y prefiere, en cambio, variantes, modulaciones particulares para nombrar el resultado de ese proceso de escritura añoso - Mariana Enriquez considera a La hermana menor un "perfil biográfico" (2016 Web); Osvaldo Baigorria llama "biografía fallida" a Sobre Sánchez (2012:7); para Christian Ferrer, El inmoralista y La amargura metódica son "informes confidenciales" (2016 Web)-, a Strafacce, en cambio, la adscripción genérica parece tenerlo sin cuidado, tanto que el título es, limpio de ironías, una reivindicación (tautológica) del género: Osvaldo Lamborghini, una biografía.

Cuando Enriquez, Ferrer, Baigorria no reconocen haber escrito una biografía, ¿con qué modelo comparan su quehacer para establecer esa distinción? Por haber declinado la pretensión de totalidad, Enriquez niega a La hermana menor esas credenciales (2016 Web); Ferrer, incrédulo, ofrece sus reparos: "nadie puede escribir biografías porque toda vida es inexpugnable" (2016 Web); en el caso de Baigorria, una pieza perdida pero la que cifra por completo la vida de Néstor Sánchez: los años oscuros de vagabundeo en París, Los Ángeles, Nueva York- desbarata de cuajo su empresa biográfica (2018:150). En estas negativas parece subyacer la idea de que la aspiración de totalidad es un sine qua non de la biografía que, candorosa, sigue creyendo que una vida puede ser representada. Como la de Strafacce sobre Osvaldo Lamborghini, dicta el cristalizado "deber ser" del género, toda biografía que se precie está obligada a seguir, día a día, desde el nacimiento hasta la muerte, a su sujeto. El modelo anglosajón (Dosse, 2007; Edel 1990), tal como lo prefiere y practica Strafacce, aun con la vida breve de Lamborghini, aun con su literatura evanescente - "de significantes y borrado de identidades", la describe Julio Premat (2009:161)-, parece ser el único a salvo de ambigüedades y cautelas. Pero, por lo mismo, ¿no le convendría una revisión?

Habría, en segundo lugar, otro "sin cuidado" que me interesa indagar aquí: se trata de la creencia de Strafacce, sin fisuras, de que la biografía pertenece a la Historia, de que su biografía es un libro de Historia exceptuado, por lo tanto, de cualquier intromisión "novelesca". En una conversación epistolar que mantuvimos a fines de 2018, a propósito del tono neutro, ecuánime, elegido para contar la vida de Lamborghini, Strafacce razonaba que:

Si la vida de Osvaldo Lamborghini fue lo suficientemente discontinua y barroca yo, para responder aquella pregunta liminar a la que vos le das la importancia que tiene (¿cómo habrá sido una persona que escribía así?), tenía que borrarme en lo posible de mi texto, ser preciso y servicial con mi lector, tenía que escribir un libro útil. A fin de cuentas, se trataba de un libro de Historia (de la Literatura).

(Comunicación personal, 6 de diciembre de 2018)

Más recientemente, en un ciclo de charlas en línea sobre Osvaldo Lamborghini organizado por los críticos e investigadores Rafael Arce y Agustina Pérez, cuya apertura estuvo a cargo de Strafacce, a mi pregunta retransmitida (¿cómo había resuelto la tensión historia/novela en la biografía?), respondió, sin mayores detalles, con ligereza, que no tuvo que lidiar con esa ambigüedad, que creyó haberse mantenido firme en la línea histórica ${ }^{3}$. En una sintonía similar, las reseñas periodísticas y los escasos estudios críticos aparecidos al momento de publicación de la biografía, reconocían, casi con unanimidad, el entramado de dos líneas narrativas, la de la vida y la de la obra, y discutían acerca de su reciprocidad o repelencia (si el hecho de que se hiciera lugar al 
análisis minucioso de la obra de Lamborghini contribuía o no a la lectura de corrido de ese relato de largo aliento, o si interrumpía, como a intervalos, su fluidez, quebrándolo4); pero no se preguntaban por esas otras líneas sustanciales del género, la histórica y la novelesca, constitutivas de su característica nota impura, de su hibridez irremediable en tanto, y en términos simples, la vida se vuelve relato, se organiza narrativamente, utilizando los recursos propios de la ficción (Edel, 1984:172)5.

Resulta extraña la confianza de Strafacce en la positividad histórica de la biografía, no sólo porque es alguien enterado del discurso teórico-crítico sobre el género -si lo incomoda, si reacciona contra él, es porque lo ha leído, aunque diga que no lo maneja o que no está capacitado para ejercerlo (Web, 2018)-, sino porque, además, es un gran novelista. Autor de El crimen de la negra reguera (Beatriz Viterbo, 1999), La boliviana (Mansalva, 2008), La escuela neolacaniana de Buenos Aires (Blatt \& Ríos, 2017), la práctica novelística le es incluso más familiar que la biográfica a la que, asegura, fue "de la figura al género" - no al revés- $y$, por ahora, no piensa volver (comunicación personal). Esa confianza se vuelve más extraña aun cuando hasta los historiadores reconocen (y lidian con) la ambivalencia de su propia disciplina, y por lo tanto, de la biografía como práctica historiográfica. Así, para Giovanni Levi, la biografía constituye "el paso privilegiado por el cual los cuestionamientos y las técnicas propias de la literatura se plantean a la historiografía" (1989:1326). En la misma línea, de acuerdo con François Dosse, la epistemología histórica se tensa entre su polo científico y su polo de ficción, y la escritura biográfica se presenta como "un buen campo de experimentación para el historiador que puede evaluar el carácter ambivalente de su disciplina" (2007:24). Un historiador biógrafo (Dosse escribió las biografías de Michel de Certeau, Paul Ricoeur, Gilles Deleuze y Félix Guattari) inevitablemente acude a la ficción porque "es imposible restituir la riqueza y complejidad de la vida real del biografiado" (25). La biografía se ubica, entonces, en un lugar intermedio, tensada entre la voluntad de "verdad" - el pacto ficcional acuerda que el relato remite a "lo verificable" (Lejeune, 1975), el "referente real", pesa- y la narración que, además de tomar prestados los recursos ficcionales de la novela, al hacerlo, reflexiona Hayden White (2003) desde la metahistoria, también produce ficción.

Sin embargo, Strafacce, seguro de haberse mantenido fiel en la huella histórica, sin "derrapes novelescos" a lo largo de ochocientas páginas, desatiende esta ambigüedad. Me pregunto, entonces, si es el trabajo de archivo, la forma de acceder a él y su posterior emergencia en el relato de la vida ajena, el que alienta la ilusión de objetividad que liga el género a la Historia y preside (decide) la forma monumental de esta biografía. Es decir, el retorno controversial de Strafacce a un modelo tradicional como es la biografía anglosajona del siglo XIX cuando en la literatura latinoamericana se están produciendo movimientos, experimentaciones formales en las escrituras de vida que configuran una "genealogía alternativa", tal como señala Antonio Marcos Pereira (2018) refiriéndose a aquellas biografías que dramatizan el ejercicio biográfico $\mathrm{y}$, por lo mismo, problematizan el género desde su interior. Recalar en un punto de vista alejado de la omnisciencia decimonónica, clausurar la linealidad cronológica, incorporar la historia de la investigación, recortar un tramo de vida, son algunas de las variables con las que las biografías que entronizan la "poética del proceso" (23) renuevan el género. Desde este lugar, repienso qué relación hay entre la forma de $L a$ hermana menor con las posibilidades que tuvo Enriquez de acceder a los archivos de la vida de Silvina Ocampo intermediados por Ernesto Montequin, albacea amable pero celoso. "Quizás -conjetura Enriquez- quiera hacer una biografía, él tiene los 
documentos y materiales para un trabajo exhaustivo. El mío no lo es: la idea del libro es otra, es más bien un prisma de Silvinas" (2016 Web). La "forma facetada" (Ibíd.) de La hermana menor se propone inseparable de la renuncia preliminar a la totalidad, pretensión que, por otra parte, ni Enriquez ni Leila Guerriero, editora de la colección Vidas ajenas, aseguran haber tenido ${ }^{6}$. Repienso, también, en Baigorria y su rastreo de la épica vagabunda de Néstor Sánchez, figura literalmente huidiza. Desde un escenario inestable - las desconectadas islas del Delta del Tigre- y con un archivo acotado (el testimonio de personas cercanas a Sánchez, el de su hijo Claudio, la obra, enigmática, del propio Sánchez, y la consulta de cierta bibliografía crítica), el biógrafo acude, como a un salvavidas, al relato de la investigación de la vida ajena para intercalarlo en el relato de esa vida, así como a la puesta en paralelo de la deriva de Sánchez con su propia experiencia trashumante en la década del 70 hacia los territorios de la contracultura norteamericana. Baigorria, que sabe hacer de la necesidad, virtud, vuelve productiva la falta basal avivando "la imaginación de la forma", "esa es toda la imaginación permitida a un biógrafo”, sentencia Leon Edel (1984:186). La biografía fallida, por poco nonata, desafía sus propios límites y se transfigura, al final, en "postautobiografía" (2012:7).

Por contraste, el archivo con el que trabaja Strafacce es exuberante. Las últimas páginas reservan su catalogación minuciosa: fuentes documentales (archivos públicos, privados -de, entre muchos, César Aira, Tamara Kamenszain, Héctor Libertella; Elvira Lamborghini; Hanna Muck-, archivos personales -el suyo y los manuscritos, agendas, libretas, libros subrayados y papeles sueltos de Lamborghini fotocopiados-, abundante correspondencia); fuentes testimoniales del núcleo más íntimo (la familia, los amigos, las parejas, los colegas), fuentes bibliográficas y publicaciones periódicas que serán citados en extenso para lograr un relato "lo más autónomo posible" (Strafacce 2008: 17). El catálogo proliferante y los generosos agradecimientos dan cuenta del acceso privilegiado a las fuentes documentales y testimoniales con los que Strafacce construye su "archivo-Lamborghini". La gran disponibilidad archivística con que la hybris documental del biógrafo se vio correspondida, sin dudas, es definitoria de la forma monumental de esta biografía que ha suscitado el desconcierto crítico.

Como si se tratara de una exhaustiva biografía "de superficies”, en "¿Qué hacer con el archivo de una vida?", Julia Musitano (2019) sostiene que el acceso irrestricto al archivo en cierto modo ahogó la potencia imaginaria del novelista Strafacce. Al no renunciar a la ilusión de totalidad, no sólo se perdió de explotar la rareza de un personaje como Lamborghini sino, además, recayó en el tipo de crítica propia de la biografía anglosajona:

Strafacce trabaja cada uno de los capítulos con la intención de explicar, con carácter de crítica biograficista, aquello que lo llevó a Lamborghini a escribir tal o cual cosa; de interpretar la obra a través de la vida. (...) En el sentido inverso, Strafacce busca en lo literario su conexión con la vida. (208-209)

El entrelazamiento cronológico de la vida y la obra tributario de una causalidad teleológica sin mediaciones también parece servir a Julio Premat (2009). Según su análisis, después de la muerte de Lamborghini en 1985, la mitificación de su vida funcionó como un recurso para trazar ecos biográficos que pudieran darle legibilidad al extremismo de sus textos:

Las peculiaridades de su vida se fueron volviendo un espacio de insistentes interrogantes, hasta tal punto que el novelista Ricardo Strafacce ha escrito una 
biografía de 1200 páginas sobre él (lo que es por lo menos paradójico tratándose, otra vez, de un escritor de significantes y de borrado de identidades). (161)

Sin embargo, aun admitiendo que el archivo construido no sea proporcional a su sujeto (si es que algo así fuera mensurable), que tal desmesura no sea representativa de la vida breve y la obra discontinua de Lamborghini - "Cada vida adopta su propia forma, un biógrafo debe encontrar la forma literaria ideal y única que la expresará”, reza el cuarto principio de Edel (1984:23)-; aun avalando que la desmedida pasión arqueológica, la necesidad de registrarlo todo sin resto, sin que nada se pierda, pueda volverse un mal, como diagnostica Jacques Derrida (1995), el prólogo y el apartado "Sistema de citas y notas. Régimen tipográfico. Posibilidades de una lectura transversal" elucidan, en parte, los motivos cardinales por los cuales Strafacce no estuvo dispuesto a hacer ciertas concesiones. La confianza en que el conocimiento del referente real de textos de fuerte impronta autobiográfica y la reposición de su génesis ayudan a comprender la obra (2008:12) es acompañada por una voluntad de igual magnitud. Strafacce se propuso erosionar el mito de Osvaldo Lamborghini como escritor maldito de creaciones ex nihilo (El Fiord sería el caso paradigmático). La pesquisa entre papeles sueltos de una literatura fragmentaria necesariamente lo compelió a realizar un trabajo de exhumación que, como mínimo, pudiera dilucidar la fecha de escritura de los textos. Así, una primera cronología ordenadora emergía del caos. ¿Qué más efectivo que la facticidad de las fuentes documentales, la contundencia de la letra escrita -incluso, por sobre la del testimonio oral- para disipar el gaseoso y oscurecido mito?, se convencía la mentalidad biográfica de Strafacce. Contra la poderosa leyenda negra, el poder de los hechos sellado en la prueba escrita, el tesón para reconstruir los escenarios-contexto de producción de la obra como si se tratasen de "escenas de alumbramiento" de causalidad ejemplar", la impasibilidad de la voz y, sobre todo, el ordenamiento cronológico de los sucesos de vida, fueron los recursos narrativos y estructurales con los que dar batalla. "Historizar el mito para neutralizarlo", podría ser la consignia.

El contramito guió la escritura biográfica de Strafacce. “Osvaldo Lamborghini, treinta y cuatro años, separado de su mujer y de su hija, sin empleo, sin dinero, sin domicilio previsible, dos libros brevísimos, escaso material inédito (...)" (2008: 358). La época no ofrecía las condiciones de recepción de una obra dispersa, fragmentaria y, en más de un sentido, revolucionaria. Como escritor, desengaña el contramito, fue uno fracasado y póstumo. Strafacce sigue la pista de una visión temprana de Lamborghini que, en carta a César Aira de febrero de 1977, caía en la cuenta de que:

Escribo, pero todo lo que escribo pertenece al género de los 'inéditos', los textos póstumos de un gran escritor [...]. Escrito como si ya estuviera muerto y canonizado, pero como no siempre o casi nunca logro leerme así, lo que ocurre es una sensación de completo derrumbe. El único y escaso consuelo sobreviene cuando pienso que a la literatura argentina le faltaba este escritor que estoy inventando. Una sombra, un escritor apócrifo. (citado en Strafacce 2008:483)

De acuerdo con Dosse, la imaginación biográfica se activa cuando hay lagunas, períodos de tiempo inaccesibles, oscuridades: "se requiere explícitamente la imaginación para disimular las insuficiencias documentales y la imposible resurrección del pasado" (2007:41). Pero la laguna documental -que, así formulada, seguiría anhelando la restitución de una totalidad imposible - no parece haber sido el problema de Strafacce; al contrario, el riesgo debió haber sido lidiar con el fárrago documental de esa vida, aprender a interrogarlo para darle una dirección y mantenerse en ella. El 
cuestionamiento a esta biografía monumental es, en todo caso, el no haber logrado la plasticidad necesaria para dotar a su personaje de "efecto de vida" (19). Es como si Strafacce se hubiera quedado en la superficie y no hubiera podido (o querido) penetrar en la vida interior de Lamborghini, intimar con él. La conjetura (de la que Borges hizo un género), "fuente principalísima", asegura en el prólogo, cuando los testimonios eran inconsistentes, cuando se tornaba imposible desambiguar ciertos hechos, cuando las lagunas no podían saldarse, fue su máxima concesión a la imaginación ${ }^{8}$. Las potencias novelescas sosegadas por el apego al archivo. Desde ese amarre, la simulación de la vida se habría rendido ante la summa biográfica.

Otros biógrafos de la totalidad, como Edel, que dedicó veinte años a investigar y a escribir (en cinco tomos) la vida de Henry James, o Benoît Peeters quien, en menos tiempo, hizo lo propio con la vida de Derrida, cuentan, como si fueran "apéndices" biográficos, el proceso de la investigación -Edel lo hace en "El taller personal", segunda parte de Vidas ajenas, y Peeters en el diario Tres años con Derrida (algo que Strafacce sustrae ya que, como narrador omnisciente de la vida ajena, no se permite la autorreferencialidad, ni siquiera en libro aparte) $-y$, con sus diferencias, llegan, no obstante, a una misma idea cerrada: las biografías literarias imitan la vida a la manera de un novelista. Claro que con esto no quieren decir que haya libertad para inventar episodios -el biógrafo sigue "atado de pies y manos" (Woolf 2012: 202)-, sino, de nuevo, que su única licencia es "la imaginación de la forma".

Caigo en la cuenta, ahora, de que, probablemente, Strafacce desvió el sentido de mi pregunta por la tensión entre la ficción y los hechos en que la hibridez biográfica se vuelve indecidible. La perplejidad, la rápida desestimación, indican que habrá tomado el término "novelesco" en el sentido convencional de "ficción" (de "falsedad", "mentira"), libre invención de episodios que no ocurrieron, inadmisible para la ética de cualquier biógrafo. De ahí la contundencia defensiva del "creo haberme mantenido firme en la huella de la Historia" que me devolvió a aquella conversación personal: “(...) tenía que borrarme en lo posible de mi texto, ser preciso y servicial con mi lector, tenía que escribir un libro útil. A fin de cuentas, se trataba de un libro de Historia (de la Literatura)" 9

Hundimiento, mimetismo, insípida glosa, ¿cayó Strafacce en las "trampas del archivo"? (Farge 1991: 56), ¿hasta qué punto podemos afirmar que la desmesura documental apagó la imaginación novelesca? Si pensamos, con Didi-Huberman, en el carácter construido del archivo (2007: 8), ¿acaso no se despliegan las primeras imaginaciones en esa construcción: en la recopilación, selección, jerarquización, ordenamiento y necesaria escritura de esa experiencia? Creo, en cambio, que la desmesura del archivo hace que la vida de Osvaldo Lamborghini se organice en esta biografía a la manera de un "expediente judicial" cuyos documentos registran, cronológicamente, la historia de un proceso, género familiar para el biógrafo-abogado Strafacce. "El abogado y el escritor se llevan de maravillas -alega en una entrevista-. Se prestan la ropa y las frases, comparten vicios, amores y deudas." (Chacón $2014 \mathrm{Web}$ ). Si algo caracteriza a un expediente es la ilusión de totalidad tramada por su cronología puntillosa y su exhaustividad, el cuidado obsesivo porque haya registro de cada una de las actuaciones que robustecen el proceso judicial. La biografía-expediente, en cierto modo, regresa al origen legal del archivo, el archivo judicial del siglo XVIII, formado por "la acumulación, hoja suelta tras hoja suelta, de demandas, procesos, interrogatorios, informaciones y sentencias" (Farge, 1991:8), y resignifica la elección del modelo 
anglosajón del género. El formato expediente evita a Strafacce sacrificar la materialidad de los documentos que emergen en el cuerpo del texto a veces como prueba, otras, como parte de la diégesis narrativa, siempre con la voluntad de favorecer al lector que, por su cuenta, no podría acceder a ellos con facilidad. Con este convite bacanal, Osvaldo Lamborghini, una biografía es, también, una fuente de consulta para futuras investigaciones. Funciona, en sí misma, como un archivo. La evidencia del contacto físico con los documentos, "la fase más primaria de la investigación, la más sucia", según Lila Caimari (2017: 15), no obstante, se beneficia de la cohesión narrativa. Un relato avanza a paso firme por la huella de la Historia: no es mero montaje o collage, no es un catálogo, no es una biografía-dossier (Peeters, 2020:182).

Si al biografía es forma, si, como afirma Judith Podlubne, "la biografía adquiere su forma configurando la vida de su sujeto" (2018: 2), y el vínculo biógrafo-biografiado se dibuja, en filigrana, en esa forma, la bio-expediente de Strafacce devela una de las facetas de ese lazo. Strafacce se proyectaría, así, como abogado defensor cuyos esfuerzos profesionales estarían puestos al servicio de desmitificar la leyenda negra de Lamborghini y hacerle lugar en la Historia de la Literatura Argentina (sintomáticamente, el final de la biografía se ocupa de las exclusiones literarias protagonizadas por el defendido poco antes de morir) ${ }^{10}$. "Hacer justicia", después de todo, es una de las motivaciones usuales de la empresa biográfica, ¿qué más apropiado para ello que tener, a nuestro favor, un biógrafo-abogado?

Escribir, en el siglo XXI, una biografía al estilo anglosajón, además de obedecer al gusto lector de Strafacce (prefiere el Rimbaud de Graham Robb antes que el Rimbaud de Alain Boreir), es un gesto deliberadamente anacrónico. En la estela airiana de la innovación ${ }^{11}$, en la estela borgeana del Pierre Menard, Osvaldo Lamborghini, una biografía se arroja a la aventura de la forma y hace su apuesta vanguardista.

\section{BIBLIOGRAFÍA}

Aira, Cesar, “Ars narrativa”, Criterion n 8, 1994a, p. 26-30.

---, “La innovación”, Boletín, nº 4, 1994b, Rosario, Centro de Estudios de Teoría y Crítica Literaria, Facultad de Humanidades y Artes, Universidad Nacional de Rosario, p. 165-170.

---, “La nueva escritura", Boletín, nº 8, octubre de 2000, Rosario, Centro de Estudios de Teoría y Crítica Literaria, Facultad de Humanidades y Artes, Universidad Nacional de Rosario, p. 165- 170.

Baigorria, Osvaldo, Sobre Sánchez, Buenos Aires, Mansalva, 2012.

Contreras, Sandra, Las vueltas de César Aira, Rosario, Beatriz Viterbo, 2002.

Caimari, Lila, La vida en el archivo. Goces, tedios y desvíos en el oficio de la Historia, Buenos Aires, Siglo XXI, 2017.

Chacón, Pablo, "Nunca tuve otro tema que el arte de la novela", Entrevista a Ricardo Strafacce, 22 de enero de 2014, Web. Consultado el 17 de mayo de 2020. 
Viana, Debret; Gruppo, Silvina; Torres, Fernando y Toledo, Ariel, Entrevista a Ricardo Strafacce, La desterrada, 13 de septiembre de 2018, Web. Consultado el 16 de abril 2020.

Derrida, Jacques, Mal de archivo. Una impresión freudiana, Madrid, Trotta, 1997, traducción de Francisco Vidarte Fernández.

Didi-Huberman, Goerges, “El archivo arde”, 2007, traducción de Juan Ennis para la Cátedra de Filología Hispánica de la Universidad Nacional de La Plata, Web.

Dosse, François, El arte de la biografía, México, Universidad Iberoamericana, 2007.

Edel, Leon, Vidas ajenas. Principia biographica, México, Fondo de Cultura Económica, 1990.

Farge, Arlette, La atracción del archivo, Valencia, Edicions Alfons El Magnànim, Institució Valenciana d'Estudis i Investigació, 1991, traducción de Ana Montero Bosch.

Fontana, Patricio, "La biógrafa cautelosa: Mariana Enriquez retrata a Silvina Ocampo", en Nora Avaro, Judith Podlubne y Julia Musitano (comps.), Un arte vulnerable. La biografía como forma, Rosario, Nube Negra, 2018, p. 193-205.

Idez, Ariel, “Historia de O”, Radar Libros. Página12, 4 de enero 2009, Web. Consultado el 15 de mayo de 2019.

Lejeune, Phillippe, "El pacto autobiográfico", El pacto autobiográfico y otros estudios, Madrid, Megazul-Endymion, 1984, traducción de Ana Torrent, p. 49-87.

Levi, Giovanni, "Los usos de la biografía”, Annales ESC, nº 6, noviembre de 1989, México, Instituto Nacional de Antropología e Historia, p. 1325- 1336.

Lezcano, Walter, "De Silvina Ocampo a Osvaldo Lamborghini, las mejores biografías de escritores", La Nación, 3 de agosto de 2016, Web. Consultado el 20 de mayo de 2020.

Munaro, Augusto, “Entrevista a Ricardo Strafacce por su biografía de Osvaldo Lamborghini”, Asesinos íntimos, 2010, Blog, Web. Consultado el 3 de julio de 2020.

Musitano, Julia, “¿Qué hacer con el archivo de una vida? Sobre Lamborghini. Una biografía de Ricardo Strafacce”, Estudios de Teoría Literaria. Revista digital: artes, letras y humanidades, n¹6, vol. 8, julio de 2019, Mar del Plata, Departamento de Letras, Facultad de Humanidades, Universidad Nacional de Mar del Plata, p. 204-214.

Peeters, Benoît, Tres años con Derrida. Los cuadernos de un biógrafo, Buenos Aires, Ubu ediciones, 2020, traducción de Vicenç Tuset.

Peller, Diego, "El indiscreto encanto de la biografía", Otra parte. Revista de Letras y Artes, n 16, 2008-2009. Web, consultado el 20 de marzo de 2019.

Pereira, Antonio Marcos, “La poética del proceso", en Nora Avaro, Judith Podlubne y Julia Musitano (comps.), Un arte vulnerable. La biografía como forma, Rosario, Nube Negra, 2018, p. 19-30. Premat, Julio, “Lamborghini: Lacan con Macedonio", Héroes sin atributos. Figuras de autor en la literatura argentina, Buenos Aires, Fondo de Cultura Económica, 2009, p. 135-166.

Podlubne, Judith, “Presentación”, en Nora Avaro, Judith Podlubne y Julia Musitano (comps.), Un arte vulnerable. La biografía como forma, Revista Orbis Tertius $\mathrm{n}^{\circ} 23$, año 27, 2018. Web, consultado el 5 de junio de 2020 .

Rancière, Jacques, "El historiador, la literatura y el género historiográfico", Política de la literatura, Buenos Aires, Libros del Zorzal, 2011, traducción de Marcelo G. Burello, Lucía Vogelfang y J. L. Caputo, p. 247-268. 
Rodríguez, Fermín, "Ricardo Strafacce. Osvaldo Lamborghini, una biografía”, Los inrockuptibles, 31 de mayo de 2010. Web, consultado el 7 de junio de 2019.

Strafacce, Ricardo, Osvaldo Lamborghini, una biografía, Buenos Aires, Mansalva, 2008.

White, Hyden, "El texto histórico como artefacto literario", El texto histórico como artefacto literario y otros escritos, Barcelona, Paidós, 2003, traducción de Verónica Tozzi y Nicolás Lavagnino, p. 107-137.

Woolf, Virginia, "El arte de la biografía", La muerte de la polilla y otros ensayos, Buenos Aires, La Bestia Equilátera, 2012, traducción de Teresa Arijón, p. 201-211.

\section{NOTAS}

1. Entre otras, pueden consultarse las entrevistas a Ricardo Strafacce de Pablo Chacón y Augusto Munaro.

2. Me refiero al incipiente desarrollo que la producción biográfica registra en la literatura argentina actual, específicamente, bajo la modalidad biografías de escritores escritas por escritores. En las últimas décadas, en efecto, se percibe un incremento de esta modalidad del género si consideramos la publicación en 2003 de la biografía de César Aira sobre Alejandra Pizarnik; en 2007, Barón Biza, el inmoralista, de Christian Ferrer (reeditada en 2016); en 2012, Sobre Sánchez, de Osvaldo Baigorria; en 2014, La hermana menor. Un retrato de Silvina Ocampo, de Mariana Enriquez y La amargura metódica. Vida y Obra de Ezequiel Martínez Estrada, de Christian Ferrer; en 2018, Mastronardi, de Miguel Ángel Petrecca y Un atleta de las letras. Biografía literaria de Juan Filloy, de Ariel Magnus.

3. "Episodios" se propone como un ciclo de charlas en línea en torno a ciertas obras de Osvaldo Lamborghini. La apertura a cargo de Ricardo Strafacce tuvo lugar el viernes 3 de julio de 2020 por la plataforma Zoom.

4. Al respecto, ver los artículos de Ariel Idez (2009); Diego Peller (2019) y Fermín Rodríguez (2010).

5. Para un abordaje más complejo acerca de la noción de vida y su relación con la escritura desde la perspectiva de la teoría literaria y la filosofía del lenguaje, recomiendo la lectura de Podlubne (2018).

6. Al respecto, ver Patricio Fontana (2018). Basándose en la nota periodística de Walter Lescano aquí citada, Fontana se pregunta cuánta totalidad es necesaria para que un texto deje de ser un "perfil biográfico" y pase a ser una biografía: "Habría, pues, según la autora, dos elementos que alejarían su texto de lo que sería cabalmente una biografía: la no pretensión de totalidad y el hecho de aportar "una mirada antes que nada"”; “sólo los "perfiles biográficos" proponen una "mirada" sobre el biografiado?; ¿acaso no toda biografía es, indefectiblemente, una mirada -un punto de vista- sobre el biografiado?" (198).

7. Esto es, de acuerdo con Rancière (2011: 254), cuando un conjunto de condiciones se implican en un único acontecimiento, a diferencia de la causalidad lineal según la cual un acontecimiento se liga a otro siguiendo una lógica de causa-consecuencia..

8. En un futuro trabajo indagaré acerca de la relación entre la conjetura como "fuente principalísima" en esta biografía, Strafacce como lector de Borges y la conjetura borgeana, y la ética del biógrafo vinculada a los excesos del archivo.

9. ¿Escandalizaría a Strafacce la lectura de esta biografía por parte de Ariel Idez (2009 Web) como "una de las mejores novelas de los últimos años"?: “(...)A estos efectos concurren los buenos oficios de Strafacce, que aúna un trabajo de investigación rigurosísimo y un lúcido análisis crítico de los textos con una escritura fluida, plena de recursos narrativos y el aporte de la singular vida 
de su biografiado, quien asumió a conciencia el estigma del artista genial y maldito y lo encarnó hasta sus últimas consecuencias."

10. Lamborghini fue excluido del artículo de Germán García "Últimas lecturas. Las almas en pena", publicado en la revista Anamorfosis en 1984, en el que reseñaba a un conjunto de escritores argentinos más o menos contemporáneos (815), y de la historia y antología de la narrativa hispanoamericana entre 1916 y 1981 que la editorial siglo XXI le había encargado al puertorriqueño Ángel Flores. La obra tendría 8 volúmenes y en la selección de los autores y los textos y en el Prólogo a cada volumen colaborarían escritores argentinos (Héctor Libertella, Beatriz Sarlo), uruguayos, paraguayos y exiliados de Hispanoamérica. Lamborghini encabezaba el preparado por Libertella, pero Flores decidió vetar a El Fiord por tremendista y pornográfico (815-816).

11. Ver, por ejemplo, Aira (2000); (1994a) y (1994b); y también Contreras (2002).

\section{RESÚMENES}

El presente artículo se propone indagar acerca de la incidencia del acceso irrestricto al archivo en la escritura biográfica de Ricardo Strafacce sobre Osvaldo Lamborghini teniendo en cuenta que la forma de esta biografía se corresponde con el modelo ortodoxo anglosajón. Contar una vida en grandes dimensiones, cronológica y monumentalmente, en el siglo XXI, acaso pueda resignificarse como un gesto por demás aventurado que se acerca, en más de un sentido, a la "aventura de la forma" propia de las "biografías del proceso" (Pereira 2018). Derivado de ello, en un segundo momento, interesa adentrarse en la tensión entre biografía e historia en tanto el propio autor le atribuye la categoría de "libro de Historia de Literatura Argentina". El afán historizador que, sostuve en otra ocasión, intima con el propósito de erosionar el mito de escritor maldito de Lamborghini, compone una "biografía expediente" en la que el biógrafo-abogado ejerce su defensa.

Le présent article vise à étudier l'incidence du libre accès aux archives dans les écrits biographiques de Ricardo Strafacce sur Osvaldo Lamborghini, en tenant compte du fait que la forme de cette biographie correspond au modèle orthodoxe anglo-saxon. Raconter l'histoire d'une vie en grandes dimensions, chronologiquement et monumentalement, au XXIe siècle, peut parfois être interprété comme un geste trop aventureux qui se rapproche, dans plus d'un sens, à l'"aventure de la forme" typique des "biographies du processus" (Pereira 2018). Dans un deuxième temps, nous aborderons la tension entre biographie et histoire, puisque l'auteur luimême lui attribue la catégorie de "Livre d'Histoire de la Littérature Argentine". L'empressement de l'historien à éroder le mythe du maudit écrivain de Lamborghini, compose un "dossier biographique" dans lequel l'avocat biographe exerce sa défense.

This article aims to investigate the incidence of unrestricted access to the archive in Ricardo Strafacce's biographical writing on Osvaldo Lamborghini, bearing in mind that the form of this biography corresponds to the Anglo-Saxon orthodox model. Telling a life in great dimensions, chronologically and monumentally, in the XXI century, perhaps it can be re-signified as an extremely adventurous gesture that approaches, in more than one sense, the "adventure of form" typical of the "biographies of the process" (Pereira 2018). Derived from this, in a second moment, it is interesting to delve into the tension between biography and history as the author 
himself attributes the category of "Book of History of Argentine Literature". The historicizing desire that, I argued on another occasion, intimates with the purpose of eroding the myth of Lamborghini's cursed writer, composes a "expedient biography" in which the biographer-lawyer exercises his defense.

ÍNDICE

Palabras claves: tensión novela/historia, archivo, biografía expediente, biógrafo-abogado Keywords: tension novel / history, archive, biography file, biographer-lawyer

Mots-clés: tension roman/histoire, archives, dossier biographie, biographe-avocat

\section{AUTOR}

NIEVES BATTISTONI

UNR- IECH/CONICET

nievesbattistoni@gmail.com 